\title{
Design and Creative Methods as a Practice of Liminality in
}

Community-Academic Research Projects

Dr Busayawan Lam (Corresponding Author)

Design Department, Brunel University, Uxbridge, UK,

Kingston Lane, Uxbridge, UB8 3PH, Email:Busayawan.lam@brunel.ac.uk

Professor Martin Phillips

Geography Department, University of Leicester, Leicester, UK

Professor Mihaela Kelemen

Keele Management School, Keele University, Newcastle-under-Lyme, UK

Dr Theodore Zamenopoulos

Design Group, The Open University, Milton Keynes, UK

Susan Moffat

New Vic Borderlines, New Vic Theatre, Newcastle-under-Lyme, UK

Sophia de Sousa

The Glass-House Community Led Design, London, UK 
Busayawam Lam is a senior lecturer and the Director of Teaching and Learning at the Design Department Brunel University. She has extensive experience in conducting design research and recommending strategic directions for various organizations. Her research interests include codesign and community-led design.

Martin Phillips is Professor of Human Geography and the Landscape and Community Research Theme Leader. His research interests cover rural social and cultural geography, historical geography, society/environment relations and philosophy in geography.

Mihaela Kelemen is Professor of Management and Public Engagement at Keele University. Her research is underpinned by a Pragmatist philosophy and a collaborative form of co-inquiry which taps into narrative methods, dramaturgical approaches, organizational theories and community studies, and explores what is considered 'actionable' knowledge by communities.

Theodore Zamenopoulos is a Senior Lecturer in design at The Open University. His research focuses on the conditions and approaches that enable civic engagement in design. He has been involved in a number of research projects around empowerment through co-design.

Susan Moffat is the founder and the director of New Vic Borderlines at the New Vic Theatre in Staffordshire. New Vic Borderlines is the theatre's outreach department responding directly to the needs of the community locally and to the issues nationally and globally which have an impact on the lives of ordinary people.

Sophia de Sousa is the Chief Executive of The Glass-House Community Led Design. The Glass-House is a national charity dedicated to connecting people with the design of their places, and connecting design with people. Sophia is also a leader in the field of research on community-led, participatory and co-design practices.

This work was supported by the Arts and Humanities Research Council's Connected Communities Grants: AH/K006541/1, AH/K006711/1 and AH/K006185/1

The authors would like to thank following project partners for their valuable contributions: Victoria Thomas and Charlotte Blakemore, Tidworth Mums; Alison Gilchrist, Community Development Consultant; Cherish Risi-Elford and Claire McEnoy,Wokingham Borough Council; Ian Montgomery, Shinfield Parish Council; Jim Robertson, The Churches' Regional Commission in the North East; Joyce Stretton, Army Welfare Service; Margaret Riley and Dr Chris Buttanshaw, Kindle Partnerships; Mary Cullen and Tom Bray, Wiltshire Council; Rob Errington, HealthWORKS Newcastle 


\title{
Design and Creative Methods as a Practice of Liminality in Community-Academic Research Projects
}

\author{
This paper aims to explore the types of spaces and experiences that are created by \\ design and creative practices. More specifically, it focuses on how design and \\ creative practices can engender transformations in the mindset, knowledge, \\ emotions and social relations of people who participate in such practices. To do \\ this, the paper investigates the concepts of liminality and liminal spaces, and the \\ relationships between design/creative methods and liminal spaces using insights \\ from four case studies. The results reveal that design and creative practices may \\ create liminal spaces in many ways, such as neutralizing the working \\ environments, encouraging people to experiment with new ideas and helping \\ them express themselves more freely.
}

Keywords: design methods; creative methods; co-design; liminal space

\section{Introduction}

There have been a growing number of studies describing design and creative practices as transformative for individuals, their social relations and society. For instance, there are numerous studies that look at transformations in the social capital and wellbeing of people because of their engagement with art-based practices such as music, drama or drawing (e.g. Hampshire and Matthijsse 2010; Daykin et al. 2008; Staricoff 2004). Design practitioners and researchers are making similar claims that design, and more specifically engagement in design, is transformative. Hilary Cottam, as the director of Design Council's RED unit, argued that the application of design approaches to address complex social challenges can transform the life of people by transforming their social relations (Design Council 2015). Engagement in design is described as transformative for communities (e.g. Manzini 2015), human organizations (e.g. Selloni and Corubolo 2017) but also more broadly for society, as design can evoke behavioural, cultural and political change (e.g. Disalvo 2015). The root of these transformations is not always the 
output of the design activity (e.g. a new service/product) but also the engagement process of people in design and creative practices itself. This engagement has been claimed to have an important impact on emotions (e.g. confidence), skills and social structures that underlie the capacity of people and communities to shape their own futures (e.g. Ehn, Nilsson, and Topgaard 2014; Rezai and Khazaei 2017).

While experts agree that higher levels of participation lead to more profound results (Bontoft 2006; Sanders and Simon 2009), there is no theoretical account of the nature and scope of these transformations that take place during and after design and creative practices, or what the key characteristics of these practices are that effect these transformations. In this paper, we seek to explore the nature of these transformations through the lens of liminality, a useful concept for investigating relationships between participation in design and creative activities, and changes in participants' perceptions and behaviours. We will apply the liminality concept to describe how the engagement with design and creative practices in community research could be transformative for individuals and communities. We begin by investigating the concept of liminality and liminal spaces, followed by reviewing the relationships between design and creative methods and liminal spaces. We aim to illustrate how liminal spaces are formed and operate within these design and creative methods. The paper could help advance the understanding of liminal spaces, as well as design and creative methods for future studies, especially in the context of community research.

\section{Liminality and Liminal Space}

The idea of liminality was originated by Van Gennep (1960). He regarded liminality as a threshold stage that marked a transition in the life of any person or cohort of people. His 'rites of passage' refer to rituals that mark a person's transition from one state or 
status to another (Van Gennep 1960). During the transitional stage, people no longer hold the social, political, religious, economic and/or educational status they previously had. Van Gennep distinguished three key phases in a rite of passage: separation, transition, and incorporation, which have been further elaborated by Turner (1967):

- The separation stage is described as an ambiguous state (or preliminal) - a person faces an unknown circumstance, where existing knowledge, norms, values and rules no longer apply.

- The transition stage is the adaption or incorporation of new norms, rules and values (or liminal) - a person is separated from his/her old self but tries to adapt to new norms, rules and values.

- The incorporation stage is the pre-integration stage (or postliminal) - a person has changed as he/she has internalised new rules, values and norms.

The concept of liminality puts emphasis on looking at 'processes' in order to describe and explain social phenomena (Thomassen 2009). Turner (1974) particularly linked these processes with creative and artistic activities or spaces where these activities take place. The concepts of liminality and liminal spaces have attracted attention from a range of perspectives, with the former being not only identified by Thomassen (2009) as a 'master concept' in the social and political sciences, but also circulating across a range of arts and humanities disciplines, e.g. transformational education (Meyer, Land, and Baillie 2009), media and performance studies (Coman, 2008), and creativity writing and cultural studies (McKenzie 2007).

Seeing liminality as a process or a journey (from separation to incorporation) enables this concept to be explored in various contexts. Since liminality can be seen as a transition from one status to the next, recent studies suggested that many modern life 
social exercises, namely theatre, literature, music, games and mass media (e.g. television programmes) could create liminal spaces and take people through a transition period through immersive experience. Turner (1974) described this kind of liminal-like experiences as 'luminoid' events. Thomassen (2009) argues that some caution is needed if the notion of 'luminoid' is treated as approximation of a liminal experience rather than a genuine transformational experience. This paper will use the tripartite structure of liminality to describe transitions in design experiences.

\section{Design and Creative Practices as Liminal Experiences/Spaces}

Many experts argue that immersive experiences, especially design and creative experiences, have potential to take individuals through liminal spaces. Turner (1974, 65) observed that the luminoid can be 'an independent domain of creative activities' which often takes place in 'neutral spaces' (e.g. laboratories) that are set aside from the mainstream activities. This idea is well aligned with recent studies which suggest that settings that are different from everyday routines could make people feel safe and more willing to experiment with new/unusual ideas (Levi 2008; Sanders 2012).

To provide more specific insights into how creative experiences could create liminal spaces, design education can be used as an example. Osmond and Tovey (2015) observed that the design process shares several common elements with liminal spaces. Their study showed that design students went through three stages of liminality in order to learn how to think and work like professional designers. The cognitive skills (e.g. design thinking) were often taught through problem-based learning in a form of a design project. Design students are generally presented with design projects, which are designed to take them out of their comfort zone and enter new territories - or preliminal stage. In every design project, there are certain degrees of uncertainty because some 
aspects (e.g. user demands) are at least partially unknown. The learners often report that they have gone through a state of struggle, confusion and disorientation, which are key characteristics of 'liminality' (Osmond 2015). The state of understanding has been (at least partially) suspended, since previous knowledge from other projects might not be applied to different contexts. The transformation from a state of confusion to a breakthrough was often described as a creative leap or a 'eureka' moment. A designer is able to come up with an innovative idea when he/she is able to discard 'old' ways of seeing problems, and integrate what was previously perceived as scattered aspects, together and in a new way (De Bono 1995).

Similar observations can be made for co-design practices. Co-design is generally defined as "the creativity of designers and people not trained in design working together in the design development process” (Sanders and Stappers 2008, 6). Taking non-designers (e.g. users) through the co-design process is rather similar to the way in which young designers are trained. Co-design can be seen as a practice that guides people, especially those not trained in design, through different stages of liminality.

\section{The impact of Liminal Spaces Created by Design and Creative Methods}

A number of recent studies suggest that taking communities through immersive creative experiences could lead to positive effects. For instance, Boyle and Harris (2009) point out taking people through the co-design and co-production process could encourage self-help attitudes and promote self-confidence and positive behaviour changes. Moreover, Sanders and Simon (2009) observe that the creative experiences encourage people to start asking more open-ended questions that lead to new explorations.

Atkinson and Robson (2012) report that creative methods (in this case, art-based interventions) have a transformative potential due to their ability to take people through 
the liminal space. They conclude that creative art-based interventions could impact people's personal social and emotional well-being. By engaging people in a time, space and set of activities that are different from their everyday routine, they face different rules, values and relations. This new set of rules, values and relations enable people to express their feelings and identities more freely. The authors point out that the transformations within a liminal time-space are only valuable if they are transferable back into everyday life. They stress that continual reinforcement and protection must be put in place to achieve long lasting benefits of the transformations. Atkinson and Robson (ibid, 1351) observe that "a flexible temporality did not undermine the development and delivery of the other defining aspects (of the liminality)”. Furthermore, creative activities could also attract disengaged members of the community or 'hard to reach' groups (e.g. ex-offenders) to participate in community projects (Bontoft 2006).

While many studies record the journey through liminal spaces on an individual basis, Levi (2008) suggests that transformational experiences could also take place at group level. Transformational group experiences happen when participants collectively think and act together. The study pointed out that physical spaces play a significant role in creating transformational group experiences. For example, the space should be welcoming and different from participants' daily lives. It should contain suitable facilities for group activities, e.g. sufficient spaces for sitting and walking side by side and materials that could be called upon to evoke meanings.

Sanders (2012) suggests that in order to help people think and work collectively, there is a need to help them build a mutual goal or a collective vision together. Having a big picture helps connect all ideas together, people can think together as a group. Her study also notes that physical spaces and objects play a crucial role in promoting 
transformational group experiences (ibid). Sanders goes beyond physical spaces to discuss requirements in terms of social/cultural spaces, e.g. trust among the participants, mutual respect between participants and sense of ownership in the collective vision. Both Levi and Sanders' studies support the idea of the 'neutral' space proposed by Turner (1974). This idea of providing a neutral and safe space for people to experiment with new, unfamiliar ideas will be explored further through our case study examples. We suggest that immersive design and creative experience could be used as a means to take people across liminal spaces at both individual and group levels.

\section{Liminality and Liminal Spaces in Community Research}

This section provides four case studies. Two of them employed co-design as the main methodology and two employed other creative methods, namely Cultural Animation and Gaming. The first co-design case study and the Cultural Animation case study examine how the liminal space might operate within the short-term engagement with co-design and creative methods. The second co-design case study investigates how liminal space might operate within the longer term of engagement with co-design methods. The last case study explores potential application of Gaming in community research in a broader sense. All case studies are derived from projects funded by the Arts and Humanities Research Council in the UK.

The overarching premise in the development of all four case studies was that codesign and creative practices could instigate transformations in the mindset, knowledge, emotions and social relations of people who participate in such projects. Each project was staged into a series of activities that aimed to help participants to go through a process of separation from existing norms and practices and activities leading them to a process of transition and incorporation of new norms and practices. The activities were 
designed to instigate this progression (from a pre-liminal to a post-liminal phase), but each activity did not have a unique function (pre-liminal, liminal or post liminal). In the following, the cases studies report on the nature of these activities and the associated transformative outcomes.

\section{Co-Design in Community Research}

This case study was part of the project titled 'Unearth Hidden Assets through Community Co-design and Co-production’ which aimed to explore how co-design and co-production could be used to support asset-based community development. The work discussed in this section is taken from a co-design workshop, which aimed to engage different stakeholders living in Shinfield Rise, Wokingham, UK, to uncover underutilized assets in their community. The 2-hours workshop involved eight participants who represented various stakeholders in the community (e.g. community development workers, local borough councillors, members of the community panel and local residents) and explored whether co-design could help people recognize strengths and potentials of their community. The workshop planning and participant recruitment were carried out with support from the Commissioning Officer, Wokingham Borough Council. It contained three main activities: open discussion, model-making and the cocreation of future plans.

\section{Preliminal Phase}

The workshop began with an introduction of the project, followed by open discussions about the community and its underutilized assets. Informal conversations also included how these assets could be mobilized and/or better utilized. The workshop was designed to take all participants out of their traditional community meeting practices. The workshop was organized in the Community Flat - a public space provided by the local 
council to support community activities. This setting provided an informal atmosphere to the whole workshop. The setting also helped take people out of their daily routines to a certain degree. Although the Community Flat was owned by the local council, it was not seen as a governmental building. Since it was used by the local youth club and for informal events (e.g. cooking classes), it was considered the community’s property. Hence, it was perceived as a 'neutral' space for all stakeholders.

\section{Liminal Phase}

Next, LEGO SERIOUS PLAY, a simple creative task, was purposely chosen to help people uncover and visualize underutilized assets. Model-making, which is not part of participants' daily routines, helped people separate themselves from their usual mindset, and encouraged them to see things differently and to think outside the box. We introduced the following series of disruptions:

- The simple and playful tasks, which did not require any specialist knowledge and skills, helped participants leave their professional knowledge and their roles in the community behind. They also put every participant on an equal footing, since no hierarchical consideration was required. To a certain degree, they helped reduce psychological and/or emotional barriers between different groups.

- The open-ended questions invited participants to look at their community with a fresh pair of eyes.

- Since every LEGO model they built was treated as 'community asset', this helped participants think positively about their community and start recognizing value in everyday things they often take for granted - such as community development staff and volunteers, social networks and green spaces. 
The participants appeared to be able to leave their professional knowledge and their roles in the community behind, since none of the assets that they identified were directly linked with their professional work. Their ways of thinking matched the characteristics of people going through the liminal stage - they were able to discard existing knowledge and conventional ways of thinking. The participants were also able to match underutilized assets with critical needs in the area. They were also able to connect issues that were not previously linked. This ability matched the characteristics of a journey through liminal spaces (Osmond and Turner 2010). Arguably, the codesign methods have the potential to help participants restructure their ways of thinking about their community and how to address issues in the area.

\section{Postliminal Phase}

Many assets were identified in a short period of time. The creative outcomes led to productive discussions and plans on how to better utilize unused/unwanted/discarded items and spaces. A number of positive comments came out at the end of the workshop. Several participants felt that it was one of the most positive and productive discussions they had about their area. The comments from participants suggested a certain degree of transformation, which is one of the key characteristics of the post-liminal state. Several participants stated that the creative exercises changed their ways of thinking about their community and provided them with new practices on how to deal with issues in their areas - see a comment from the Community Development Worker below:

"Being involved in the research has helped me to see things differently particularly in relation to using the language of 'assets' to communicate with people, and the community has also welcomed this new, positive 'mindset". 
It was observed that active participation in the co-design process, could lead to a number of positive effects. For example, the co-design methods did encourage people to ask more open-ended questions and explore ways to address that challenges themselves. Participants felt genuinely proud of themselves to be able to uncover many assets and come up with innovative ways to mobilize them in a short period of time. The co-design tasks helped people recognize and appreciate their own creativity, which is crucial to the asset-based community development.

\section{Cultural Animation in Community Research}

This case study focuses on the 'Bridging the Gap between Academic Theory and Community Relevance: Fresh Insights from American Pragmatism’ project. The study investigated coping mechanisms of Japanese communities affected by the 2011 Tsunami. It employed the Cultural Animation methodology to provide insights into 'actionable' knowledge from community perspectives. This section discusses one specific Cultural Animation workshop conducted by four members of the project (two academics and two community practitioners) in a small town in Japan. The aim of this half-day open workshop was to capture and celebrate the stories of the people who had experienced this natural disaster. Approximately 30 local residents took part in the workshop. In this case, the participants could join and leave at any point. They generally spent 20 - 30 minutes at the workshop.

\section{Cultural Animation Methodology}

Cultural Animation is a theatre-based methodology. At the heart of Cultural Animation is the shifting of the existing status quo and the creation of safe environments where traditional knowledge hierarchies and barriers are dissolved so that new and more creative dialogues are possible and different and more useful relationships are formed 
between researchers and the community (Goulding, Kelemen, and Kiyomiya, 2017). To take people beyond the threshold of what they know and what is predictable into a 'neutral' space which is equally 'uncomfortable' for everyone, most Cultural Animation workshops often take place outside of the realms of people’s daily routines.

\section{Preliminal Phase}

To create safe environments where traditional knowledge hierarchies and barriers can be removed, new rules of engagement are often introduced through stories and games. In this case, a story was used to take people outside the realms of their daily lives. Thus, a 'tree' was chosen as the central character (see the wood cut-out tree in Figure 1) in the story due to its symbolic value in Japanese culture. The tree in this story was sad and bare and its leaves had been swept away by the river. To help it thrive, villagers were invited to create/recreate items, stories, poems and songs to give as a gift to the tree so that it could be filled with life again. This kind of request served as a new rule of engagement, designed to help people distance themselves from their daily life and usual world.

The empty tree was placed in the middle of an outdoor temporary shopping street. Nearby the tree, tables and benches with a selection of everyday objects (e.g. empty picture frames, clocks, tea-cups and candle sticks) as well as a collection of art and craft materials (e.g. tissue paper, ribbons and string,) were set up. By bringing in items and objects that are generally not associated with that space, a new meaning or a new sense of purpose was given to the space. 


\section{Liminal Phase}

Prior to the workshop, a simple invitation had been sent out. Thus, some villagers had arrived with an idea of joining in with a research workshop organized by UK universities. The presence of the tree and items disrupted what participants originally anticipated. Despite feeling confused, people began making gifts for the tree and started sharing stories with other people, which was considered uncommon for Japanese people who are generally private and reserved. Through the actions of making and creating together, an environment of equality was created. The items they created prompted questions and stories to emerge. The warmth of the connections dissolved any actual or perceived hierarchies which might have existed. As the workshop progressed the bare wooden tree became filled with drawings, poems, dolls and stories.

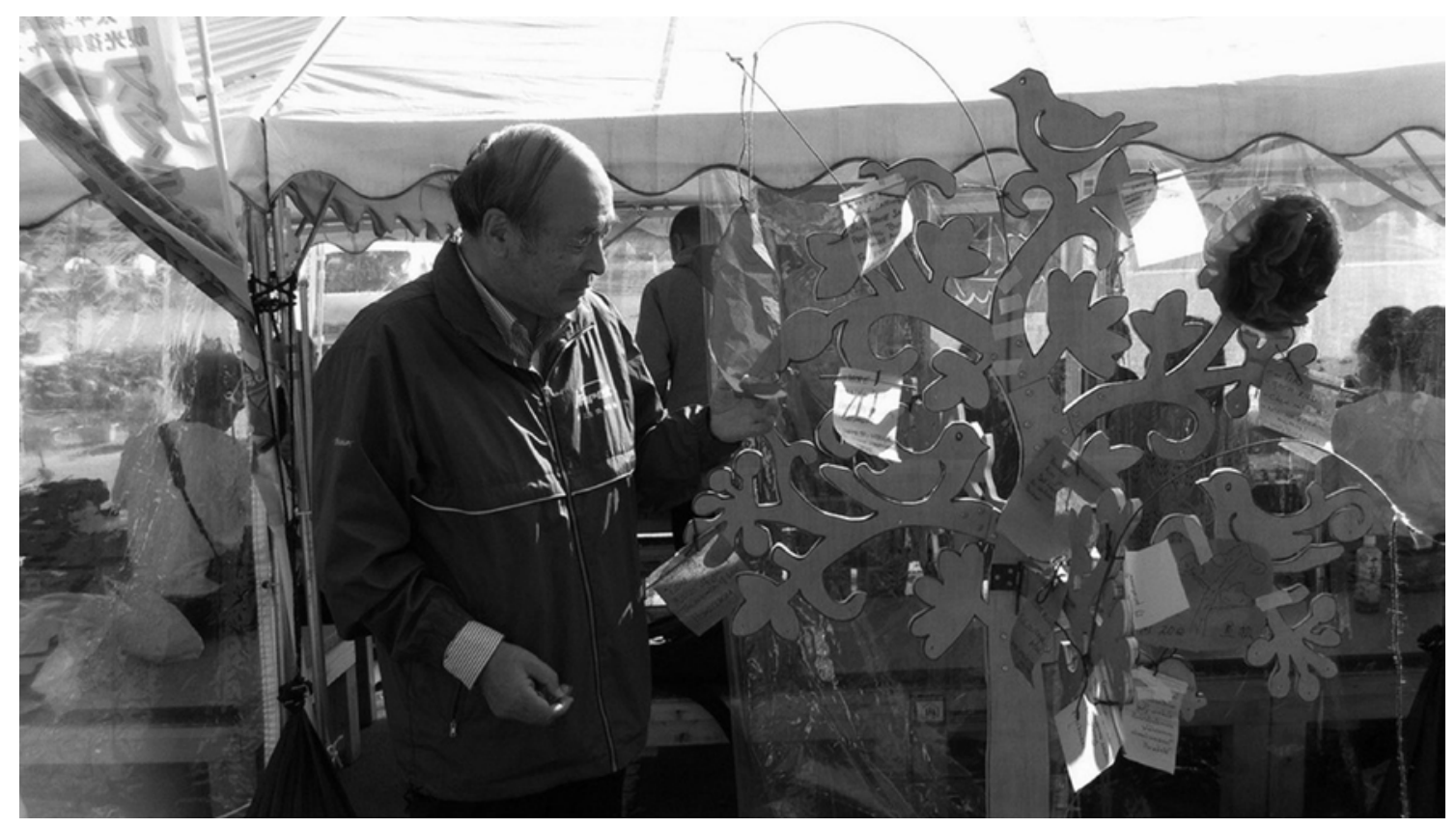

Figure 1. The tree and creative outcomes

The participants appeared to be able to leave 'usual' ways of thinking/behaving behind. It was observed that issues of language and shyness no longer posed a problem. 


\section{Postliminal Phase}

The process was democratic. The space was not dominated by a single voice or group. Moreover, people could enter the space freely and were able to be equally involved through observing and enjoying the activities taking place around them. They could contribute as much or as little as they felt able and were not compromised by the idea of correct or incorrect ways. The end result of the process was an opportunity to share the labours of their creativity together. It was observed that there was a sense of camaraderie and achievement among participants who took part in the workshop. People felt genuinely proud as they could see what had been achieved and were able to make sense of it either individually and privately, or by conversing with others. The atmosphere in the workshop had completely changed with people clapping and cheering each other as they presented their creative work. The workshop demonstrated to each person in the workshop not what was lost but what remained in place and could be used to build a better future. The changes of perceptions toward themselves and their community, as well as the sense of camaraderie and achievement among participants were probably the key impact of the Cultural Animation process. It also accelerated conditions of trust and connectedness among participants. These results suggested a certain degree of transformation, which is one of the key characteristics of the postliminal stage. This is probably the irreversible effect of the Cultural Animation methodology - see a comment from one of the participants below:

"The activities and discussions have challenged my pre-conceived ideas"

\section{Co-design in and across Civil Society Organizations}

This case study was part of the 'Scaling up Co-design' project, which aimed to design and prototype practical approaches for scaling up co-design practices within and across 
civil society organizations and their communities. The project included five researchers from 4 different academic institutions, with expertise in architecture, human computer interaction, design management and participatory design, and five directors from civil society organizations (partners) who acted as co-researchers. These were a local voluntary service council; a social enterprise that supports open source development; a network of women promoting open-source software; a national charity supporting communities engaging in placemaking; a foundation that supports independent living; and a social enterprise supporting people who are isolated and disadvantaged.

\section{Preliminal Phase}

Academic and non-academic partners have described early phases of the project as a process of 'separation' from their known ways of thinking and operating in their context. To a certain extent, this was simply because of a new context. For some partners, this was the first time that they would work together with academic partners to co-develop a research project. Moreover, the project included a diverse body of academics and civil society organizations, which contributed to a sense of ambiguity about the purpose but also the ways of working that would move this project forward.

The co-design practices at these early phases helped facilitate this separation process through the use of role-playing. During initial meetings, it was agreed that a 'basic level' of consensus was needed regarding the objectives and working practices of the project. Subsequently, an approach entitled 'Design by Consensus', which had been developed and used within the context of community-led design by one of the partner organizations (The Glass-House Community Led Design) was adapted to facilitate the co-design of the research. The process began with an exercise in which stakeholders were invited to explore the development of a fictional project, acting from the 
perspective of stakeholders other than their own. For that purpose, participants were given 'stakeholder personas' created before the meeting. Participants explored their 'priorities', ‘concerns' and 'values/principles’ from their allocated stakeholder’s standpoint and then classified each of these as 'individual' to one stakeholder, 'shared' or 'conflicting', using a large matrix. Participants used this information to create a vision for the project.

The underlying premise of this approach was that using a fictional project and adopting unfamiliar roles would help stakeholders to release their personal emotional investments, and develop some empathic understanding of other stakeholders. The process and associated materials (e.g. personas) was perceived by partners as a space that enabled everyone to share perspectives but also as a key process of separating from existing practices and negotiating possible future ways of working.

\section{Liminal Phase}

A second phase emerged as partners started exploring ideas and co-design models that could scale up the reach and impact of their organizations. During this phase, a series of visual diagrams (Figure 2) were created to depict various models of scaling up codesign practices. The generation of these models marked a transition in the mindset of partners. More specifically, all partners agreed that these models marked a transition to a shared understanding of the terms and concepts that lay at the heart of the research. This led to the idea of 'cross pollination'; a process that would enable design collaboration by sharing communities, partners, skills and other resources. Consequently, the notion of cross-pollination marked a big transformation in the relationships and working practices of partners. 


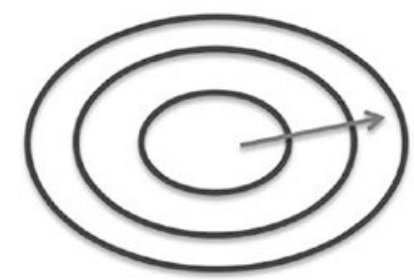

Scaling up as extending out: offering more, reaching more people

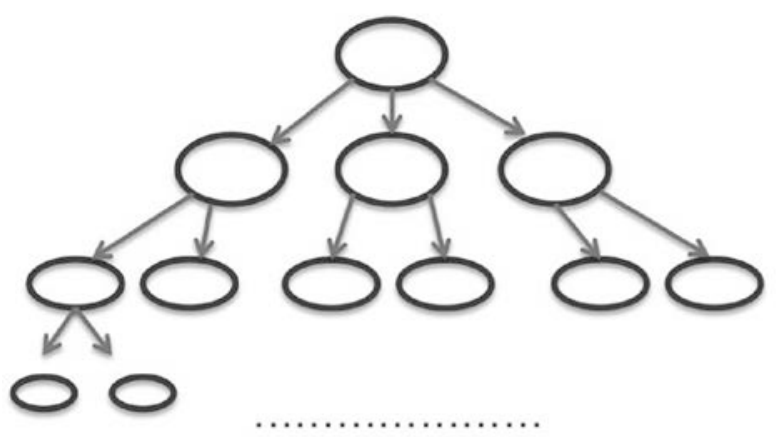

Scaling up as spreading out: cascading, a tree or pyramid model

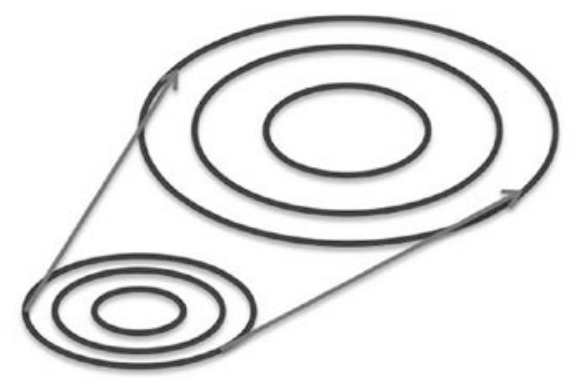

Scaling up as extending up: having a larger impact, influencing general practice (e.g. AHRC, policy makers)

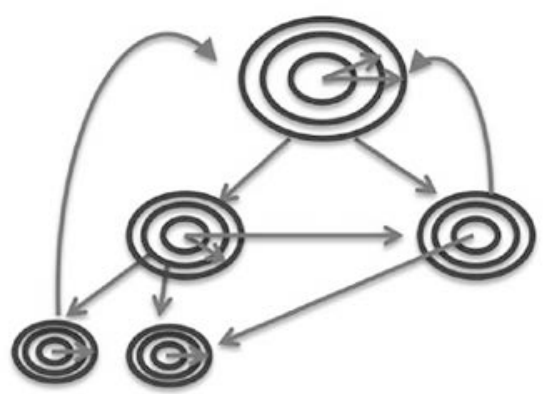

Scaling up as connecting: connecting practices at multiple levels, a network model

Figure 2. Diagrams depicting different models of scaling up co-design

\section{Postliminal Phase}

The above phase led naturally into an incorporation phase where new partnerships and models of working were adopted. Each civil society partner identified live or emerging projects in their work on the ground with communities that they felt were relevant to the line of enquiry of the research. They also identified associated assets that were important for these projects. The group then formed projects that were of particular interest and relevance to two or more partners. They considered what other practicebased and academic partners could offer to enrich the projects, and how the collaborations could contribute to joint learning, as well as individual learning and development of each partner. The partners also considered how the collaborations on the various sub-projects could help connect or 'cascade' the project to further collaborations outside the core team. Finally, they considered how the collaborations 
could enhance the reach and impact within the communities in which they were being delivered. This created a growing network of collaborations and practices that are still under development years after the completion of the project.

\section{Gaming in Community Research}

Gaming was employed in several projects funded by Arts and Humanities Council in UK under the Connected Communities programme. For example, a game titled “Glossopoly” (based on the structure of the game Monopoly) was created and employed to facilitate several community studies (see Figure 3). Glossopoly was designed to facilitate discussions and reflections on relationships people have with their places in a small town called Glossop in Derbyshire in the UK. This study was carried out by a lead investigator in the field of social and cultural geography and involved various groups of people from the local community, e.g. secondary school students from Glossop and surrounding areas. In this incarnation of the game, pictures depicting famous areas in Monopoly board were replaced with pictures of local places in Glossop. As people rolled the dice, they travelled from one place to another and were asked to answer questions or perform simple tasks, e.g. drawing things they like about a particular place or describing briefly what a place means for them.

The rules of the game are flexible and can be modified to work with a wide range of audiences, e.g. school children, community development practitioners and policy makers. Similar to the previous examples, the venues and setting must be carefully selected to create a 'neutral space'. The game can be played singularly or in small groups ( $2-3$ persons). People can stay in their pre-existing groups or mix with people they do not know. 


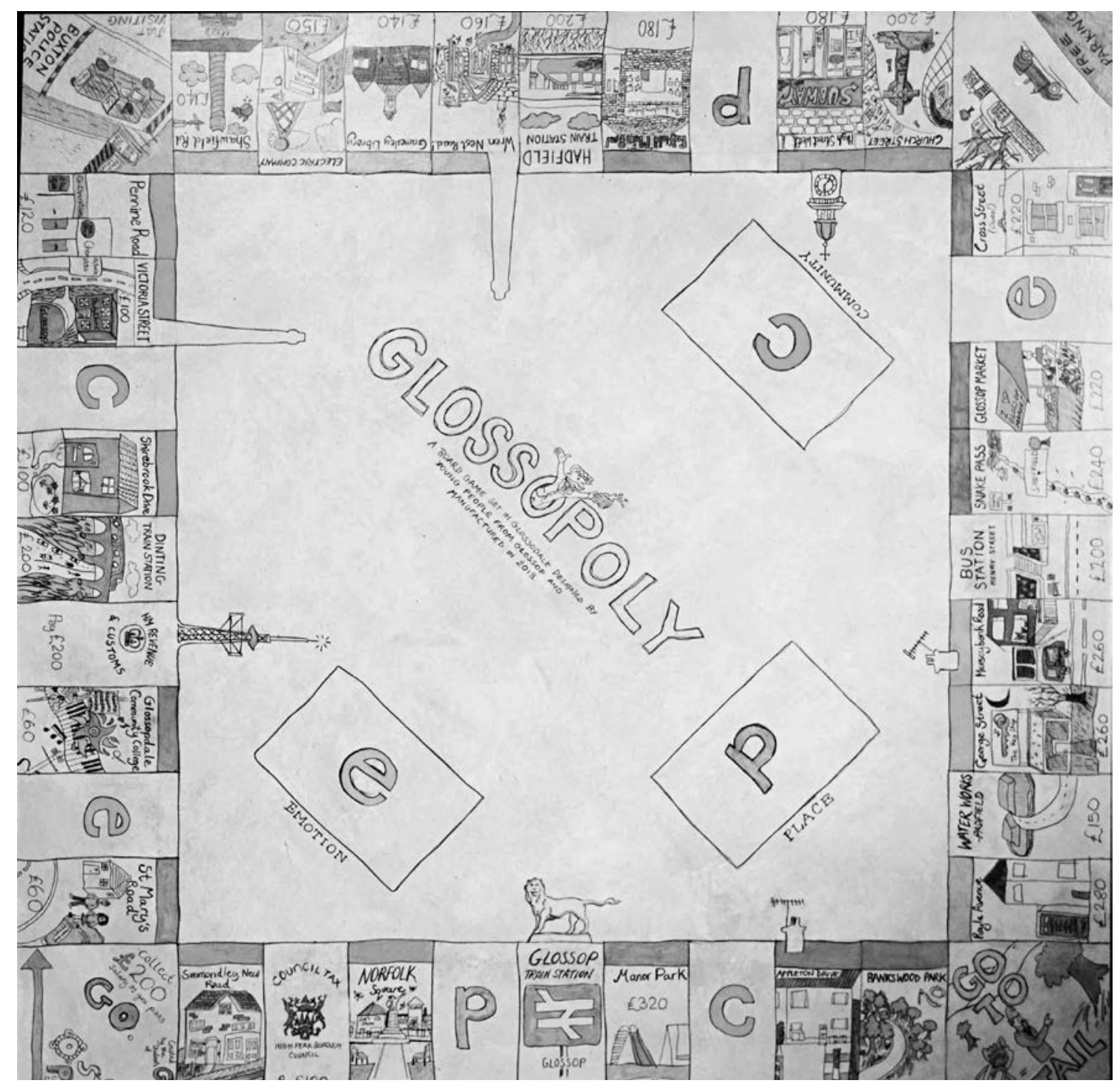

Figure 3. The ‘Glossopoly’ game

\section{Preliminal Phase}

Generally, gaming is familiar to many people, which is useful at the preliminal phase.

This is because people are asked to follow very simple rules, such as taking turns, dice throwing, being given or picking a card. On one hand, the notion of monopoly as a 'kids' game' can lead to some people not taking it seriously and, thus, are unable to separate themselves from their 'usual' selves. On the other hand, the notion of play can also encourage people to detach themselves from their reality by playing the game sometimes via a companion (e.g. friends). 


\section{Liminal Phase}

It was observed that the game could generate a number of disruptions. For example, people did not know what they would have to do until they got given a card. Moreover, topics varied according to the throw of the dice. This serendipity helped disrupt participants' lines of thought and prompt spontaneous conversations. Although the tasks appeared simple, people had to engage with views of other people, which often quickly provoked in depth discussions and/or reflections - see an example below:

"I felt I was able to express my thought very quickly with the group I was in, and then to the wider group. The questions were deep and complicated in many ways, yet they allowed us all to contribute a mixture of personal experience and more general social observation”.

During the game, people had to provide answers in a range of different ways (verbally and visually). These kinds of rules kept participants on their toes, which helped promote natural responses. People were able to detach themselves from their community/professional roles and provided honest answers.

\section{Postliminal Phase}

The end of the game was usually enforced by external conditions (e.g. time for event). A series of artefacts created as part of the game (e.g. drawings) helped act as reminders of the liminal event. Although a game might not produce new 'outcomes', it was perceived as a new process and potentially stuck in participants' memory.

\section{Discussion and Conclusion}

The applications of design and creative methods in community research projects demonstrate key characteristics of liminal spaces. To a certain extent, participants were 
able to detach themselves from existing ways of thinking, norms, values and/or rules, and adapt themselves to new ways of seeing/thinking/behaving, norms, rules and values. The transitions could be created through short-term engagements with design and creative activities and long-term engagements with a project. There was no significant difference between liminal spaces created through design and other creative methods. Liminal spaces require a creation of a 'neutral' space, where conventional rules, norms and values do not apply. In this way, people can express themselves and experiment with new ideas freely and openly. The case studies showed that spaces could be neutralized/given new meanings through design and creative methods by:

- Introducing a new set of rules which can help take people out of their everyday routine and their 'usual' ways of thinking/behaving

- Making sure that the place is not part of participants' daily routines, does not belong to any groups and/or intimidate any participants. Clever use of design props can turn everyday spaces into neutral spaces.

- Creating a level playing field for all parties by giving tasks that everyone can do without prerequisite knowledge and which are not related to their professional lives.

Immersive experiences are also required, which could be delivered through design and creative methods by:

- Giving people creative tasks which can encourage people to express themselves more freely and openly. Creative tasks can be used to help people discover their talents and help them see themselves differently. The nature of creative tasks also encourages people to explore open-ended questions. 
- Taking people out of their comfort zones by asking them to carry out creative tasks that they do not normally perform in everyday life. These kinds of tasks also encourage people to experiment with things they do not generally do.

- Providing opportunities to discuss and reflect on creative outputs. Creative outputs have proven to be effective prompts for provoking in-depth conversations and reflections about people, their community and their place. Creative outputs act as reminders of liminal spaces and people's achievements. Most people were genuinely proud of what they achieved in the short period of time.

To sum up, the paper aimed to illustrate how liminal spaces are formed and operate through design and creative methods. Design and creative methods provide 'tangible' elements to facilitate the creation of liminal spaces, e.g. props to transform everyday spaces into creative workshop spaces, creative outputs to provoke conversations, and reminders of people’s achievements and their transitions across liminal spaces. Design and creative methods also provide 'intangible' elements (such as processes and methodology) to support the creation of liminal spaces. The combination of both tangible and intangible aspects is useful in creating both a neutral space and an immersive experience.

Liminal spaces created through design and creative methods could lead to valuable impacts in terms of changing perceptions and mindset. Many participants reported that the design and creative activities had helped them change their ways of thinking about themselves, their community and their place. Other impacts were rarely mentioned. This might be due to the nature of the design and creative activities employed in these projects and/or the relatively short exposure to the design and 
creative tasks - some tasks took less than one hour to complete.

It can be seen that each method has different strengths and benefits. For example, the co-design methods are likely to generate creative outputs, which are a great reminder of participants' achievements. Cultural Animation is effective at separating people from their immediate reality through storytelling, which is an important part of the preliminal phase. Gaming is very flexible, since new rules can be easily introduced and generate more disruptions, which are crucial to the liminal phase. For researchers and practitioners working with communities, it would be useful to consider how different design and creative methods they choose may create different kinds of liminal spaces, which, in turn, lead to different kinds of transformation.

\section{References}

1. Atkinson, Sarah, and Robson, Mary. 2012. “Arts and health as a practice of liminality: Managing the spaces of transformation for social and emotional wellbeing with primary schools children.” Health \& Place 18 (6): 1348-1355.

2. Bontoft, Martin. 2006. “Open Door: The design of a co-produced health \& social care service in Grimsby”. The Big Life Group. Accessed: 2 October 2012. http:/www.thebiglifegroup.com/userfiles/file/Open\%20Door/open\%20door\%20rep ort\%20(ebook).pdf

3. Bovaird, Tony. 2007. “Beyond Engagement and Participation: User and Community Coproduction of Public Services.” Public Administration Review September/October: 846-860.

4. Boyle, David and Harris, Michael. 2009. The Challenge of Co-production. London: NESTA. 
5. Coman, Mihai. 2008. "Liminality in media studies: From everyday life to media events.” In Victor Turner and Contemporary Cultural Performance, edited by Graham St John, 94 - 108. Oxford: Berghann.

6. DiSalvo, Carl. 2015. "Disseminating research through design - challenges and opportunities learned.” Constructivist Foundations 11 (1): 22-23.

7. Daykin, Norma, Byrne, Ellie, Soteriou, Tony, and O'Connor, Susan. 2008 “The impact of art, design and environment in mental healthcare: a systematic review of the literature.” Journal of the Royal Society of Health, 128 (2): 85-94.

8. De Bono, Edward. 1995. Serious Creativity: Using the Power of Lateral Thinking to Create New Ideas. London: HarperCollins.

9. Design Council (2015) RED PAPER 01 HEALTH: Co-creating Services. London: Design Council.

10. Ehn, Pelle, Nilsson, Elisabet M., and Topgaard, Richard. ed. 2014. Making Futures: Marginal Notes on Innovation, Design, and Democracy. Cambridge (MA): MIT Press.

11. Goulding Christina, Kelemen Mihaela, Kiyomiya Toru. 2017. Community based responses to the Japanese Tsunami: a bottom up approach. European Journal of Operational Research. DOI: 10.1016/j.jproman.2016.09.005

12. Hampshire, Katherine Rebecca and Matthijsse, Mathilde. 2010. "Can arts projects improve young people’s wellbeing? A social capital approach.” Social Science \& Medicine 71 (4): 708-716.

13. Levi, Renee. 2008. “The Power of Place: An Inquiry into the Influence of Place, Space and Environment of Collective Transformation.” PhD diss. Saybrook University. 
14. Manzini, Ezio. 2015. Design, When Everybody Designs: An Introduction to Design for Social Innovation. Cambridge (MA): MIT Press.

15. McKenzie, Vahri. 2007. "Liminal space: Postgraduate creative writing in Australian universities”. Limina Journal of Historical and Cultural Studies, Special Edition: $20-28$.

16. Meyer, Jan H.F., Land, Ray, and Baillie, Caroline. 2010. “Editors’ Preface: Threshold Concepts and Transformational Learning.” In Threshold Concepts and Transformational Learning, edited by Jan H.F. Meyer, Ray Land and Caroline Baillie, ix - xlii. Rotterdam: Sense Publisher.

17. Osmond, Jane. 2015. “Industrial Design and Liminal Spaces.” In Design Pedagogy, edited by Michael Tovey, 135-146. Farnham: Gower.

18. Osmond, Jane and Tovey, Michale. 2015. “The threshold of uncertainty in teaching design.” Design and Technology Education: an International Journal, 20 (2):50-57.

19. Osmond, Jane and Turner, Andrew. 2010. "The threshold concept journey in design: from identification to application.” In Threshold Concepts and Transformational Learning, edited by Jan H.F. Meyer, Ray Land and Caroline Baillie, 347-364. Rotterdam: Sense Publishers.

20. Sanders, Elizabeth B.N. 2002. “From User-Centered to Participatory Design Approaches.” In Design and the Social Sciences edited by Jorge Frascara, 1-8. London: Taylor \& Francis.

21. Sanders, Elizabeth B.N. 2012 “Creativity in Strategic Thinking.” In Enhancing the Army’s Strategic Thinking Capability: Insights to Assess, Develop, and Retain Strategic Thinkers, edited by Heather M.K. Wolters, Anna P. Grome, and Ryan M. Hinds, Research Report for U.S. Army Research Institute for the Behavioral and Social Sciences. 
22. Sanders, Elizabeth B.N. and Stappers, Pieter Jan. 2008. "Co-creation and the new landscapes of design.” Co-Design, 4 (1): 5-18.

23. Sanders, Elizabeth B.N. and Simon, George. 2009. A Social Vision for Value Cocreation in Design. Open Source Business Resource. Accessed: 9 July 2012. http://www.osbr.ca/ojs/index.php/osbr/article/view/1012/973

24. Selloni, Daniela and Corubolo, Marta 2017. Design for social enterprises. Codesigning an organizational and cultural change, The Design Journal, Pages S3005S3019; https://doi.org/10.1080/14606925.2017.1352809

25. Rezai, Maziar and Khazaei. Mitra 2017. The challenge of being activist-designer. An attempt to understand the New Role of Designer in the Social change based on current experiences, The Design Journal, Pages S3516-S3535, DOI: https://doi.org/10.1080/14606925.2017.1352855

26. Staricoff, Rosalia Lelchuk. 2004. Arts in health: a review of the medical literature. London: Arts Council England.

27. Thomassen, Bjørn. 2009. “The Uses and Meaning of Liminality.” International Political Anthropology, 2 (1): 5-28.

28. Turner, Victor. 1967. "Betwixt and between: the liminal period in rites de passage." In The Forest of Symbols: Aspects of Ndembu Ritual, edited by Victor Turner, 93111. Ithaca: Cornell University Press.

29. Turner, Victor. 1974. "Liminal to liminoid, in play, flow and rituals: an essay in comparative symbology.” Rice University Studies 60: 53-92.

30. Van Gennep, Arnold. 1960. The Rites of Passage. Chicago: University of Chicago Press. 